\title{
Analisis Retouching Foto Close Up Karya Petra Sinuraya Menggunakan Teknik Digital
}

\section{Retouching Analysis of Close Up Photos By Petra Sinuraya Using Digital Techniques}

\author{
Yesika Prebina Br Bangun* \\ Program Studi Pendidikan Seni Rupa, Jurusan Seni Rupa, Fakultas Bahasa Dan Seni \\ Universitas Negeri Medan
}

Diterima: 04 Mei 2021 Direview: 04 Mei 2021; Disetujui: 06 Agustus 2021

*Coresponding Email: yesikaprebina@gmail.com

\begin{abstract}
Abstrak
Penelitian ini bertujuan untuk mendeskripsikan konsep dan proses visualisasi teknik fotografi retouching foto close up karya Petra Sinuraya. Metode penelitian ini yaitu penelitian deskriptis analitik terhadap karya. Subjek penelitian jenis ini adalah karya fotografi retouching foto close up Petra Sinuraya. Data dianalisis secara deskriptif analitik dengan analisis presentase yang menggunakan prosedur statistic sederhana. Data diperoleh dengan menggunakan metode wawancara dan dokumentasi. Instrumen dirancang berdasarkan pedoman wawancara dan dokumentasi, dan dikembangkan berdasarkan situasi yang terjadi dilapangan. Penelitian dilakukan dengan mengambil dan menyeleksi dokumen berupa karya foto seni sebanyak 10 buah. Hasil penelitian diperoleh bahwa proses retouching foto close up yang digunakan Petra Sinuraya adalah teknik digital dengan mengasah skill lewat sentuhan Tools yang ada pada software Photoshop. Peranan komposisi dalam proses Retouching sangat penting untuk kebutuhan klien agar foto terlihat lebih menarik dihasil akhir. Adapun hal yang Petra Sinuraya lakukan dalam Retouching foto Close Up ialah dengan berbagai cara seperti Spot Hiling Brush untuk Menghaluskan Kulit, Burn and dodge tool untuk retouching mata, Dodge and Burn untuk Kontras Mencerahkan/Menggelapkan, Filter noise dan Gaussian blur - untuk kulit tanpa cela dan Patch tool untuk Menyempurnakan foto.
\end{abstract}

Kata kunci: Fotografi; Retouching; Close Up.

\begin{abstract}
This study aims to describe the concept and process of visualization of the close-up photo retouching technique by Petra Sinuraya. This research method is descriptive analytic research on the work. The subject of this type of research is Petra Sinuraya's close up photography retouching work. Data were analyzed descriptively analytic with percentage analysis using simple statistical procedures. Data obtained by using interview and documentation methods. The instrument was designed based on interview and documentation guidelines, and was developed based on situations that occurred in the field. The research was conducted by taking and selecting documents in the form of 10 pieces of art photos. The results showed that the close-up photo retouching process used by Petra Sinuraya was a digital technique by sharpening skills through the touch of tools available in Photoshop software. The role of composition in the retouching process is very important for client needs so that the photo looks more attractive in the final result. As for what Petra Sinuraya does in Close Up photo retouching is in various ways such as the Spot Hiling Brush for Smoothing the Skin, Burn and dodge tool for eye retouching, Dodge and Burn for Lightening / Darkening Contrast, filter noise and Gaussian blur - for flawless skin. and the Patch tool to enhance photos.
\end{abstract}

Keywords: Photography; Retouching; Close Up.

How to Cite: Bangun, Y.P. (2021). Analisis Retouching Foto Close Up Karya Petra Sinuraya Menggunakan Teknik Digital. Journal of Education, Humaniora and Social Sciences (JEHSS). 4(2): 629-641.

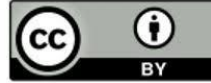




\section{PENDAHULUAN}

Perkembangan fotografi sudah tampak pada era digital yang telah memungkinkan pemotretan tanpa film. Pengambilan gambar dengan digital secara pasti meniadakan eksistensi film, negatif dan proses fotografi analog. Hal ini terjadi karena perekaman objek foto telah diambil alih oleh kamera digital yang memiliki layar sensor elektronik CCD (charge coupled device) atau CMOS (complementary metal oxide semiconductor) yang dilengkapi dengan memory card sebagai informasi data foto dengan berbagai kemampuan kapasitas simpannya. Fotografi yang prinsipnya sebagai media untuk mengabadikan dan merekam gambar, tetapi sekarang dalam perkembangannya sudah menjadi sarana untuk menuangkan ide, kreatifitas, media ekspresi dan sebagai media dalam berkesenian.

Penelitian ini memilih foto close up karena banyak hal yang diretouching, dimana akan mengkoreksi make up yang kurang rapi, rambut yang berantakan warna pada kulit dll. Adapun dari segi proses penciptaan karya ini dapat dicapai dengan memanfaatkan cara pengambilan data gambar dengan kamera digital yang memanfaatkan berbagai teknik pencahayaan. Pengambilan gambar dapat dilakukan dengan cara seni foto (memotret) objek, kemudian dengan seni editing (proses memanipulasi) objek.

Pembahasan terkait fotografi ini sebelumnya telah dipaparkan oleh Setiawan (2015) dengan judul "Analisis fotografi digital imanging surealistik karya Kicung Hartono". (Saulaka dkk, 2020) Pada penelitian ini membahas tentang konsep fotografi Kicung Hartono yang bertemakan fantasi digital imanging. Hasil dari penelitian ini yaitu teknik yang digunakan berupa digital imaging, meliputi editing dan drawing, untuk menghasilkan karya yang secara keseluruhan bernuansa surealistik sekalipun seperti pada karya seni lukis. Dengan perkembangan fotografi sekarang, memudahkan untuk mengembangkan ide kreatif dalam dunia fotografi. (Sinaga \& Triyanto, 2020)

Selanjutnya Agasi (2017) dengan judul "estetika fotografi still life pada produk online shop folk store". Pada penelitian ini merujuk pada fokus masalah tentang unsur garis, bidang, ruang dan warna pada saat pengamblan foto. Teknik pemotretan produk ini yaitu DoF (Depth of Field) betujuan untuk menciptakan kesan ruang dalam foto dengan cara menjadikan latar belakang foto blur dan DoF luas yang bertujuan untuk menampilkan keseluruhan detail objek.

Istilah fotografi berasal dari dua kata foto dan grafi yang dalam bahasa Yunani, foto berarti cahaya dan grafi berarti menulis dan melukis, sehingga fotografi dapat diartikan sebagai melukis dengan cahaya (Soelarko, 1984). Dalam fotografi, kehadiran cahaya adalah mutlak perlu, karena mulai dari pemotretan hingga pencetakan film menjadi foto, keduanya membutuhkan cahaya. Menurut Saleh (2014) fotografi terjadi berkat adanya cahaya, dan sebaliknya tidak akan ada fotografi yang lahir dari kegelapan. Berdasarkan penjelasan sebelumnya penulis menyimpulkan bahwa fotografi adalah seni melukis menggunakan cahaya yang juga merupakan salah satu bagian dari seni yang dalam prosesnya memiliki teknik- teknik dalam menciptakan kualitas sebuah karya fotografi.

Seorang fotografer bisa menghabiskan waktu bertahun-tahun untuk menguasainya teknik retouching, bagi Petra Sinuraya biasanya ini tidak hanya sekadar koreksi debu atau menghilangkan elemen lain yang tidak ingin disertakan dalam foto. Terutama saat Petra Sinuraya memotret gambar dengan sensor kotor, Petra masih dapat mengubah gambar dan menghilangkan partikel debu yang disertakan di dalamnya. Kamera yang bagus saja tidak cukup untuk hasil yang maksimal, peranan komposisi dalam retouching foto disini sangat dibutuhkan. Dalam memvisualisasikan karya fotografi menggunakan teknik retouching foto close up, yaitu dengan cara satu teknik atau tahapan editing pada photoshop yang memberikan kesan bersih dan detail pada foto. Sebenarnya retouching adalah tahapan akhir dalam sebuah editing gambar dimana aksi yang diberikan berupa peningkatan ketajaman dan kecerahan suatu objek. Teknik ini biasanya banyak digunakan oleh para fotografer-fotografer, terkhusus bagi para wedding photograph termasuk Petra Sinuraya. Beberapa Teknik yang dilakukan Petra Sinarya dalam proses retouching foto sebagai berikut: 
1. Spot hiling brush - menghaluskan kulit

2. Burn and dodge tool - untuk retouching mata

3. Dodge and burn - Kontras Mencerahkan/Menggelapkan

4. Filter noise dan Gaussian blur - untuk kulit tanpa cela

5. Patch tool - Menyempurnakan

Selanjutnya, pembahasan mengenai teknik diatas akan dibahas lebih mendalam di pembahasan selanjutnya. Adapun tujuan dari penelitian ini yaitu agar dapat mendeskripsikan proses dan spesifikasi hasil manipulasi fotografi digital dalam mengatasi permasalahan pada foto close up karya Petra Sinuraya. Ketertarikan peneliti terhadap analisis retouching foto close up ini didasarkan oleh pengolahan foto yang menurut peneliti menarik dengan memanfaatkan kemajuan teknologi sehingga foto terlihat natural walaupun sebenarnya sudah melalui proses retouch. Kepuasan klien saat menggunakan jasa si fotografer juga menjadi poin penting karena hasil yang maksimal dapat membuat klien senang karena dapat mengabadikan momen spesial mereka. Itulah sebabnya mengapa perlu dibahas mengenai retouching foto close up ini, agar lebih memperdalam ilmu dalam dunia fotografi bagi mereka yang menekuni profesi fotografi atau hanya menekuninya sebagai hobi agar dapat menghasilkan karya yang maksimal. (Agustin \& Ibrahim, 2020; Mustika \& Erdansyah, 2020).

\section{METODE PENELITIAN}

Menurut Sugiyono (2016) metode penelitian adalah cara ilmiah untuk mendapatkan data dengan tujuan dan kegunaaan tertentu. Untuk tercapainya tujuan penelitian maka diperlukan metode penelitian yang tepat. Metode tersebut dijadikan sebagai prosedur atau langkah-langkah melakukan penelitian ilmiah. Metode dalam penelitian ini adalah deskriftif kualitatif atau sering disebut dengan penelitian naturalistic karena penelitiannya dilakukan pada kondisi yang alamiah (Natural Setting). Oleh karena metode tersebut penelitian yang alamiah sesuai dengan keadaan, kondisi, situasi, dan peristiwa yang terjadi, maka dalam hal ini penulis melakukan observasi langsung pada objek penelitian. Pengamatan ini meliputi pemusatan perhatian pada teknik editing dan tool yang digunakan Petra Sinuraya dalam mengedit sebuah foto dengan menggunakan aplikasi photoshop, serta mewawancarai langsung kepada Petra Sinuraya untuk memperoleh data. Penulis juga menggali informasi berkenaan dengan proses retouching pada foto close up pre-wedding melalui sejumlah pertanyaan yang hasilnya dicatat sebagai informasi yang akurat, dan kemudian penulis juga mendeskripsikan data-data yang diperoleh berdasarkan subjek yang di teliti dengan instrument penelitian yang sudah ditentukan.

Dalam penelitian kualitatif, populasi di artikan sebagai wilayah generalisasi yang terdiri atas objek/subjek yang mempunyai kualitas dan karakter tertentu yang di tetapkan oleh peneliti untuk di pelajari dan di tarik kesimpulan (Sugiyono,2016), maka populasi atau situasi sosial yang digunakan dalam penelitian ini adalah seluruh karya foto close up pre-wedding karya Petra Sinuraya yang berjumlah 25 karya yang di anggap memiliki potensi untuk diteliti. Sampel adalah sebagian atau wakil populasi yang diteliti (Arikunto, 2006). Dinamakan penelitian sampel apabila kita bermaksud untuk menggeneralisasikan hasil penelitian sampel. Maka sampel dalam penelitian ini diambil dengan teknik purposive sampling (sampel bertujuan). Sampel berjumlah tiga softcopy file karya yaitu foto close up yang harus di edit. Penulis memilih sampel ini adalah beberapa foto yang memiliki masalah di bagian wajah yang memiliki tantangan dalam pengeditannya seperti jerawat yang cukup banyak, kulit yamg kurang halus serta foto dengan pencaayaan yang kurang.

Menurut Arikunto (2006), metode pengumpulan data adala cara yang dapat digunakan oleh peneliti untuk mengumpulkan data sebagai keterangan tentang suatu objek penelitian yang diperoleh di lokasi penelitian. Maka dari itu untuk memperoleh data, teknik dalam pengumpulan data yang dilakukan penulis adalah: Observasi atau pengamatan secara langsung tentang proses edit retouching foto close up dan mengamati proses pengeditan foto, wawancara langsung kepada responder atau subjek yang diteliti untuk memperoleh data, penulis akan menggali informasi yang berkaitan dengan retouching foto melalui sejumlah pertanyaan yang hasilnya di catat 
sebagai informasi yang penting dan akurat dan dokumentasi dari tulisan ataupun gambargambar pada saat proses retoucing berlangsung yang terkait dengan objek penelitian.Adapun tahapan analisis data yang dilakukan adalah sebagai berikut:Pengamatan terhadap karya foto close up sebagai objek penelitian; Analisis data berupa informasi yang menjelaskan tentang tools, permasalah wajah yang di retouch, serta penerapan prinsip komposisi pada hasil foto; Mendeskripsikan proses dan tahapan dalam melakukan edit retouching foto close up; dan Menyimpulkan data hasil penelitian.

\section{HASIL DAN PEMBAHASAN}

Menurut Petra Sinuraya ada beberapa hal yang harus diperhatikan sebelum pengambilan foto atau memotret, diantaranya yaitu:

a. Pencahayaan

Cahaya yang di ambil pada setiap foto yang digunakan harus datang dari arah yang sama agar memudahkan saat pengeditan gambar.

b. Lensa

Lensa yang digunakan saat pengambilan gambar sebaiknya menggunakan lensa fix agar objek lebih fokus. Atau lensa telephoto karena lensa telephoto memiliki karakter yang berfungsi memperbesar objek foto karakter ini membuat lensa telephoto banyak digunkan dalam memotret wajah portrait atau close up. Lensa telephopto bisa membuat gambar seseorang menjadi lebih menarik, karena lensa ini mengeliminasi distorsi wajah. Karena kedalaman ruang yang tipis, memotret wanita menjadi menarik karena efek lembut yang di timbulkan.

c. Angle

Pengambilan angle harus dilakukan pada tata letak objek dan lensa yang sama agar tidak merusak komposisi gambar.

d. Field of View

Field of view merupakan komposisi umum yang dilihat dari ukuran jarak lensa ke objek. Artinya sebuah objek dapat dipotret dengan jarak yang sangat dekat, dekat, jauh atau sangat jauh. Berikut ini jenis-jenis field of fiew yang umumnya digunakan:

1) Extreme Close Up

Objek dipotret dengan jarak yang sangat-sangat dekat sehingga detail objek seperti tekstur atau kerut wajah terlihat jelas.

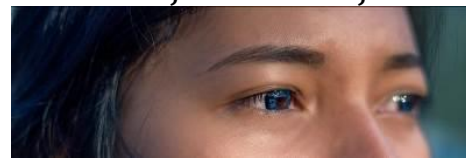

Gambar 1. Extreme Close Up

2) Head Shot

(Sumber: wakeupvisual)

Batasan foto ialah dari atas kepala hingga dagu.

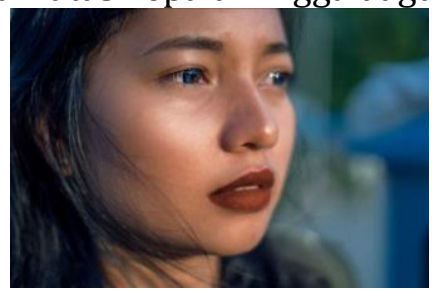

Gambar 2. Head Shot

(Sumber: wakeupvisual)

3) Close Up

Objek dipotret dengan Batasan dari atas kepala hingga bahu. Close Up memperlihatkan wajah secara penuh, sehingga sangat cocok dijadikan framing

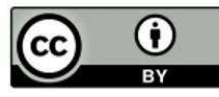


untuk memperlihatkan ekspresi. Objek menjadi sebuah perhatian dan mendominasi sedangkan background pada framing hanya sebagai pengisi dan tidak banyak berperan. Pada manusia framing ini menampilkan bagian atas bahu, leher hingga atas kepala.

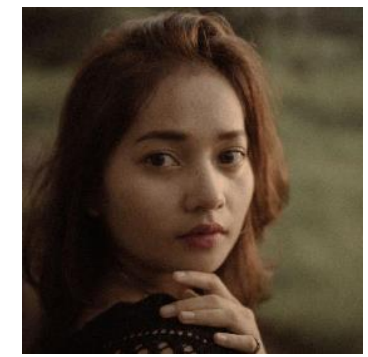

Gambar 3. Close up

(Sumber: wakeupvisual)

4) Medium Close Up

Medium Close Up memperlihatkan wajah serta bagian atas tubuh dari objek dan cukup mendominasi namun masih terlihat peran dari background. Pada manusia, framing ini menampilkan dari bagian dada hingga ujung kepala.

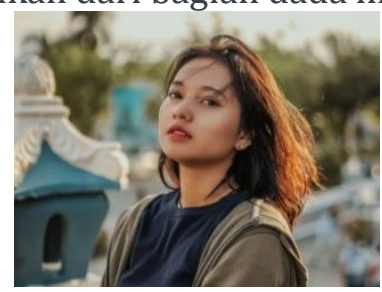

Gambar 4. Medium Close up

(Sumber: wakeupvisual)

5) Mid Shot

Objek dipotret dengan batasan dari atas kepala hingga pinggang. Disebut juga dengan foto setengah badan.

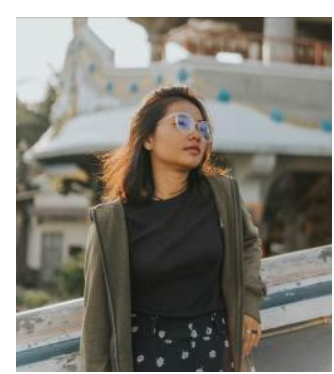

Gambar 5. Mid Shot

(Sumber: wakeupvisual)

6) Medium Shot

Objek dipotret dengan batasan dari atas kepala hingga lutut. Foto ini juga disebut dengan foto tiga perempat badan.
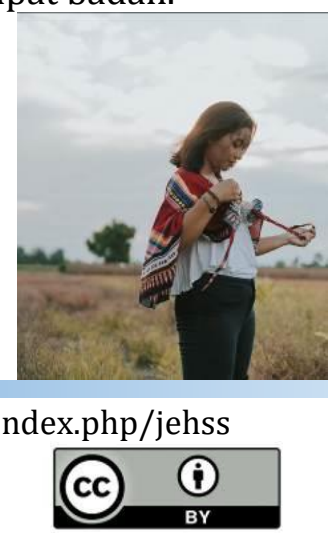
Gambar 6. Medium Shot

(Sumber: wakeupvisual)

7) Full Shot

Objek pada komposisi ini dipotret dengan Batasan dari atas kepala hingga ujung kaki. Foto ini juga disebut dengan foto seluruh badan.

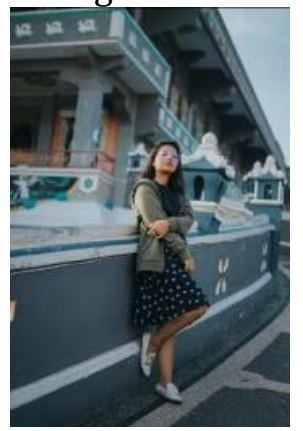

Gambar 7. Full Shot

(Sumber: wakeupvisual)

8) Long Shot

Pemotretan diambil dengan jarak yang sangat jauh dari objek. Foto yang dihasilkan akan memiliki porsi background yang sangat banyak, sementara objek utama terlihat kecil.

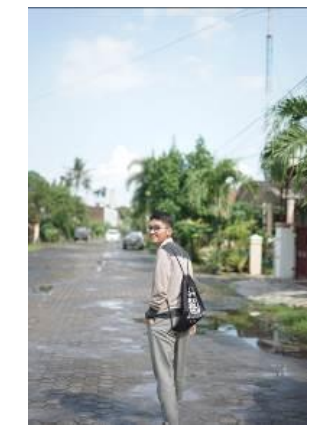

Gambar 8. Long Shot

(Sumber: wakeupvisual)

Dasar dari teori editing adalah ketika seseorang melihat satu shot atau gambar dan berlanjut ke shot lainya, secara alamiah akan menghubungkan atau berasosiasi menjadi rangkaian yang utuh. Inilah dasar sederhana dari teori editing (Dewi, 2012). Editing foto adalah merencanakan dan memilih serta menggabungkan kembali potongan gambar yang diambil para editor untuk disiarkan dalam bentuk modifikasi gambar. Ada beberapa konsep dasar pada digital editing, sebagai berikut:

1. Konsep Resolusi

2. Konsep Warna

3. KonsepLayer

4. Tool-Tool pada Software yang digunakan

Untuk dapat memperoleh hasil foto atau gambar yang lebih maksimal yang sesuai dengan keinginan, tidak jarang banyak orang yang selalu ingin mengedit foto atau gambar agar terlihat lebih sempurna dan menarik, seperti foto Wisuda, foto PraWedding, foto di kartu undangan, foto keluarga, foto brosur dan lainnya. Maka diperlukan suatu keterampilan atau pelatihan untuk dapat mengolah atau mengedit foto digital melalui pelatihan - pelatihan olah foto. Adapun software yang digunakan untuk pelatihan untuk mengolah foto digital adalah menggunakan Aplikasi Adobe Photoshop (Yuma, Eska, 2019). Adobe Photoshop, atau biasa disebut Photoshop, adalah perangkat lunak editor citra buatan Adobe Systems yang dikhususkan untuk pengeditan 6. http://mahesainstitute.web.id/ojs2/index.php/jehss mahesainstitut@gmail.com

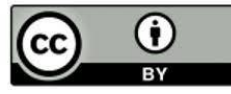


foto/ gambar dan pembuatan efek. Perangkat lunak ini banyak digunakan oleh fotografer digital dan perusahaan iklan sehingga dianggap sebagai pemimpin pasar (market leader) untuk perangkat lunak pengolah gambar/foto, dan, bersama Adobe Acrobat, dianggap sebagai produk terbaik yang pernah diproduksi oleh Adobe Systems (Ziveria, Samosir \& Rusli, 2020). Aplikasi Adobe Photoshop pada dasarnya merupakan aplikasi pengolah gambar, namun seringkali pula ia digunakan untuk mengubah tampilan suatu objek, misalnya teks atau tulisan. Aplikasi program adobe photoshop adalah program yang berorientasikan untuk mengedit, memodifikasi, maupun memanipulasi gambar atau foto, pengaturan warna yang semakin akurat, penggunaan fasilitas efek dan filter yang semakin canggih, dan fasilitas pemodifikasian tipografi teks yang semakin unuk dan fantastik (Khaeruddin, 2005). Adobe Photoshop adalah salah satu sofware untuk mengolah foto ataupun gambar, dengan adobe photoshop kita dapat memperbaiki dan mempercantik foto yang ingin kita cetak dengan menambahkan efek dalam foto tersebut, sehingga foto yang biasa menjadi sebuah foto dengan tampilan yang berbeda dan menarik (Agung, 2011).

Retouching merupakan salah satu teknik digital dalam memodifikasi atau memanipulasi sebuah foto. Retouching merupakan istilah populer terutama dalam fotografi portrait yang ditujukan untuk meningkatkan kualitas foto.

1. Mata, pada bagian ini mengapa dikatakan penting karena permasalahan yang timbul pada bagian mata ialah mata yang kuning dan kurang bersinar.

2. Skin tone, skin tone merupakan kecerahan pada warna kulit wajah permasalahn yang sering muncul disini ialah warna daripada kulit wajah dan tangan tidak singkron hal inilah yang perlu di perhatikan dapam meretouch foto

3. Tekstur kulit wajah permasalahan paling utama ialah muncul pada pada wajah yang dimana ada pori-pori yang besar, jerawat yang menumpuk, serta warna kulit yang terlihat kusam inilah indicator yang sangat perlu diperhatikan dalam meretouch foto.

4. Gigi, biasanya beberapa foto close up memperlihatkan gigi saat tersenyum dan timbul permasalahan di dalamnya ialah gigi yang kurang cerah atau kuning aspek ini yang mengharuskan editor mngedit warna pada gigi.

Proses Perwujudan. Bahan dan Alat: Perwujudan sebuah retouching foto close up tentu membutuhkan bahan, alat dan teknik penciptaan. Dalam hal ini penulis berusaha memilih hal tersebut sesuai dengan apa yang ingin dicapai pada hasil akhir. Bahan pemotretan dan pendukung pemotretan adalah bahan yang digunakan untuk mendukung objek, seperti background dan aksesoris pendukung. Bahan yang digunakan pada hasil pemotretan kertas foto cetak glossy, dengan menggunakan system cetak digital. Kamera yang diguanakan oleh Petra Sinuraya adalah kamera digital, hal ini dikarenakan untuk mempermudah proses pengelolaan foto. Kamera yang digunakan adalah Canon 7 D2, pixel 10,2 Mpx, lensa Canon EF-S 17-55mm f/2.8 IS USM dan media penyimpan SD memory cards. Komputer yang digunakan adalah komputer dengan processor AMD atlon 64 x2, RAM DDR II GB, harddisk 320 GB, DVD Rom Lite On dan monitor LG W53 series. Perangakat lunak yang digunakan dalam proses pengeditan gambar di computer adalah Adobe Photoshop CS 5. Perangkat lunak ini dipilih karena sudah familiar dalam penggunaanya dan banyak terdapat fasilitas pendukung dalam proses pengolahan gambar.

Langkah-langkah perwujudan. Beberapa Tools umum sebagai komposisi yang digunakan Petra untuk efek retouch berbeda dalam memanipulasi foto. Adapunlangkah-langkah yang diambil untuk mewujudkannya adalah sebagai berikut:

\section{AnalisisFoto 1}




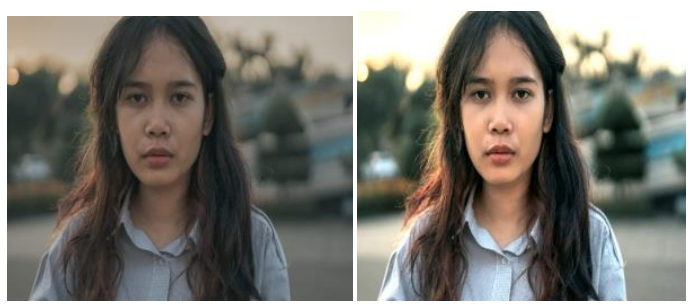

\section{Before After}

Gambar1. Before \& After

(Sumber: Petra Sinuraya)

Dalam data foto pertama ini, didapati objek (analogon) apa saja yang terdapat dalam foto tersebut, antara lain sebagai berikut :Portrait close up medium seorang gadis atau wanita; Tampak seorang gadis menggunakan kemeja berwarna abu muda; Ekspresi tatapan kosong; Latar belakang (Background) di hamparan lapang yang luas.

Makna denotasi yang didapat dengan memperhatikan beberapa yang mengungkapkan, seorang gadis menggunakan kemeja berwarna abu-abu dan dengan rambut yang terurai dengan tatapan kosong, sedang berdiri menghadap kamera serta memiliki latar belakang hamparan lapang yang luas. Gambar 1 dengan pencahayaan yang berasal dari objek gambar, dalam pencahayaan fotografi dikenal dengan istilah Sight Light. Pencahayaan normal ini dibuat dengan menerpadukan antara kecepatan rana, diafragma dan ISO, dalam unsur fotografi dikenal dengan Triangle Fotografi, dimana unsur ini menjadi bagian paling bendasar dalam pembuatan foto.

Bermacam-macam objek terdapat dalam data foto $1 \mathrm{ini}$, antara lain seperti, seorang gadis, kemeja abu, dan hamparan laparan yang luas yang menjadi latar belakang.Seorang pemuda Iran menjadi objek solo yang lebih dominan di potret melalui kamera fotografer.

Komposisi yang terdapat di dalam gambar 1 ini, menempatkan objek tampak depan dalam keseluruhan porsi gambar. Selain menjadi nilai estetisme, penempatan yang digunakan fotografer dalam menambah komposisi ini, komposisi atau penempatan objek di tengah dalam porsi keseluruhan gambar, tetapi kepekaan fotografer dalam merekam suatu momen itu menjadi lebih bermakna dan lebih berkarakter.

Dalam pemotretan diluar ruangan (Outdor), fotografer harus mengerti arah datangnya cahaya.Sumber cahaya matahari adalah sebagai mainlight (cahaya Utama). Di foto ini menggunakan Dodge Toolberfungsi untuk membuat sebuah gambar agar lebih jelas/terang.

Model wanita yang dihilangkan latar belakangnya dengan menggunakan masking. Warna awan dan objek yang telah dimasking kemudian dirubah warnanya dengan menggunakan fasilitas level, hue/saturation dan variation. Warna kuning dikaitkan dengan kecerdasan. Ide baru serta kepercayaan terhadap potensi diri. Warna ini adalah warna yang sangat positif sehingga dapat dipakai untuk menghilangkan keragu-raguan, melambangkan kejujuran, mengeliminasi pikiran negatif, dan memberi semangat. Warna biru selalu dihubungkan dengan langit dan air bagi kehidupan dan kekuatan. Warna inidiasosiasikan ketenangan dan menyejukan, Pengambilan gambar bahasa dari sudut objek tubuh samping sehingga profil wajah kelihatan jelas. Bahasa dari foto yang ada selanjutnya digabung dan disusun sedemikian rupabahasa dari beberapa gambar yaitu manusia, dan background. Prinsip-prinsip komposisi yang terdapat pada elemen gambar terdapat pada penempatan objek foto pada Rule Of Third yang terdapat daya tarik maksimum. Pusat perhatian dari objek foto ini adalah model perempuan pengambilan format pada komposisi horizontal terletak pada background, sehingga memberikan kesan apik dan mewah. Keep it simple titik yang menarik terletak pada obor api yang mengandung arti energi sebagai hasil interpretasi dari ciptaan karya tersebut. Garisgaris pada susunan bangunan terlihat secra fisik orang melihat foto kedalam gambar atau melintas gambar adalah refleksi pada leading lines.Beberapa unsur warna, raut arah gerak maka kesatuan

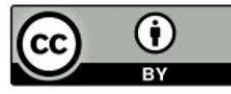


telah tercapai. Komposisi ini terbentuk dari pengemasan garis secara dinamis, yaitu pada struktur dan tekstur bangunan dan kesan gerak objek dalam irama tersebut dapat bersifat harmoni dan kontras, pengulangan (repetisi) atau variasi.

\section{AnalisisFoto 2}

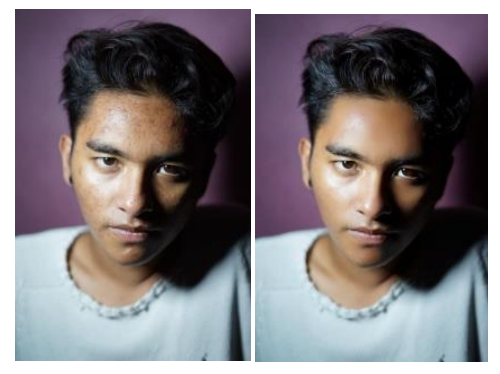

Before After

Gambar 2. Before \& After

(Sumber: Petra Sinuraya)

Dalam foto ini menggunakan Blur tool berfungsi untuk menghaluskan gambar, sehingga dengan menggunakan tool ini akan menghasilkan gambar yang halus pada area yang diinginkan. Dan Sharpen Tool berfungsi untuk menajamkan gambar, dengan tool ini kita bisa menajamkan gambar pada area yang kita inginkan, Pole seluruh bagian wajah kecuali alis mata, bulu mata, mata, lubang hidung, bibir, gigi dan bentuk wajah. Bagian-bagian tersebut harus dijaga supaya tetap tajam dan detailnya tetap terlihat. Untukk noda di wajah mengggunakan Spot Healing Brush untuk menghapus noda pada foto dan sangat berguna sekali jika ingin menghilangkan noda pada wajah.

Prinsip-prinsip komposisi yang terdapat pada elemen gambar terdapat pada penempatan objek foto pada Rule Of Third yang terdapat daya tarik maksimum. Pusat perhatian dari objek foto ini adalah wajah model perempuan pengambilan format pada komposisi horizontal terletak pada pencahayaan kesatuan objek dan background, sehingga memberikan kesan pemberani.Horizonz pada background nampak seimbang, sehingga timbul kesan radikal. Pencahayaan siluet dan senjata yang membawa mata orang melihat foto kedalam gambar atau melintas gambar adalah refleksi pada leading lines.

\section{Analisis Foto 3}

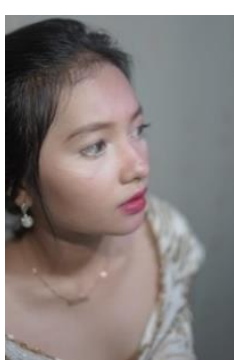

Before

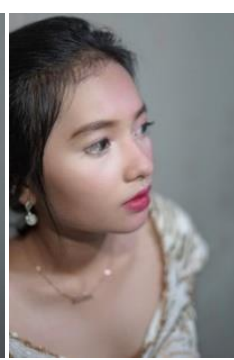

After

Gambar 3. Before \& After

(Sumber: Petra Sinuraya)

Dalam foto 3 ini menggunakanDodge Tool dengan opasitas 90\% dan Burn Tool untuk menambah kedalaman dan kontras lebih. BurnTool di gunakan di sekitar tepi gambar agar tercipta tercipta vignette halus untuk membantu mengarahkan pandangan ke pusat gambar yang terang dan menerangkan warna pada wajah, tentunya hanya pada area yang di tentukan oleh 战http://mahesainstitute.web.id/ojs2/index.php/jehss

(․) mahesainstitut@gmail.com

637

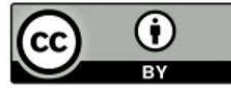


tool ini. untuk bagian hidung menggunakan Spot Healing Brush untuk menghapus noda pada foto dan sangat berguna sekali jika ingin menghilangkan noda pada wajah.Foto tersebut terdiri dari warna merah, dan baju bermotif zebra. Objek wanita nampak ekspresinya kelihatan pasrah, gerah, mellow, yang mengekspresikan pengharapan ketenangan. Pemotretan dilakukan pada objek model. Pemotretan menggunakan kecepatan rendah untuk menghasilkan efek gerakan pada bagian tangan dan raut wajah yang menghasilkan gambar lebih hidup. From the Past merupakan pilihan bagian berpose yang penulis anggap unik dan menarik. Pengambilan dilakukan dari sudut samping sehingga didapatkan gambar yang dinamis. Coloring : menyamakan warna object dan background, ini bagian paling sulit, harus dirasakan, ada tiga opsi : warna objek mengikuti background atau warna background mengikuti objek, atau kombinasi keduanya. Dalam foto ini diputuskan memakai kombinasi keduanya. Sehingga background dibuat yellow, objek juga yellow. Selanjutnya merapikan rambut (gambar helai demi helai rambutnya).Foto tersebut meletakan unsur-unsur secara bebas, tetapi tetap memelihara keseimbangan dan focus of interest. Maksud yang disampaikan dalam visualisasi karya tersebut adalah pancaran wajah yang mempesona.

\section{Prinsip Penerapan Komposisi pada Retouching foto}

Pada setiap karya dua dimensi komposisi menjadi hal terpenting yang harus diperhatikan terutama dalam memvisualisasikan kedalam karya fotografi menggunakan teknik retouching foto close up. Dengan cara editing pada photoshop memberikan kesan bersih dan detail pada foto sehingga dapat tercipta komposisi yan tepat dalam sebuah karya fotografi. Beberapa teknik yang dilakukan Petra Sinarya dalam proses retouching Foto:

\section{1) Spot Hiling Brush - Menghaluskan Kulit .}

- Langkah 1: Buat Salinan Gambar

Buka Gambar Baru di Photoshop, panel Layers menampilkan foto pada layer Background. Sebelum menghaluskan kulit, mulailah dengan menghilangkan noda yang tidak diinginkan. Untuk melindungi gambar asli, edit pada lapisan terpisah. Buat salinan layer Background dengan menekan dan menahan tombol Alt (Win) / Option (Mac) pada keyboard, klik pada layer Background, dan seret ke bawah ke ikon New Layer di bagian bawah panel Layers: Duplicating Background layer.

Setelah menggandakan layer, beri nama "Spot Healing" dan klik OK:

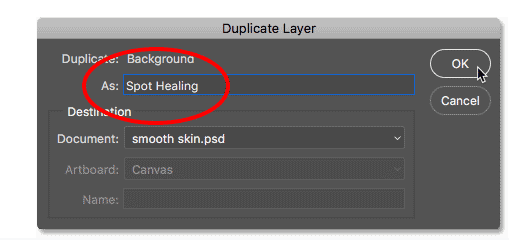

Gambar 4. Membuat Salinan Background

- Langkah2: PilihThe Spot Healing BrushdariToolbar:

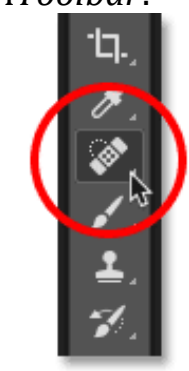

Gambar 5. MemilihSpot Healing Brush

- Langkah 3: pastikanopsi Type di Options Bar diaturkeContent-Aware:

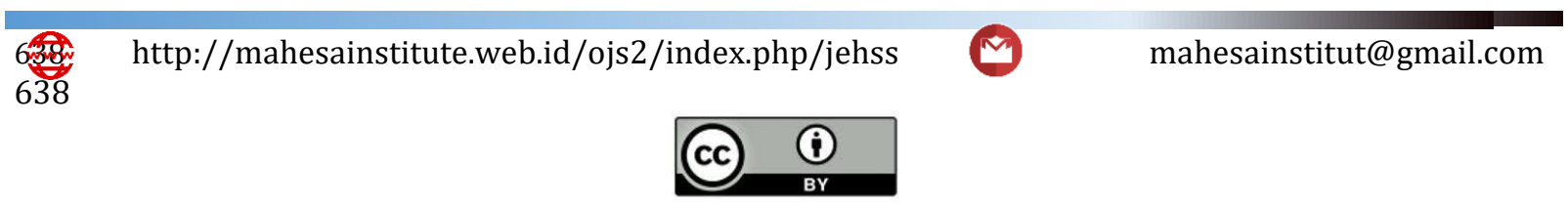




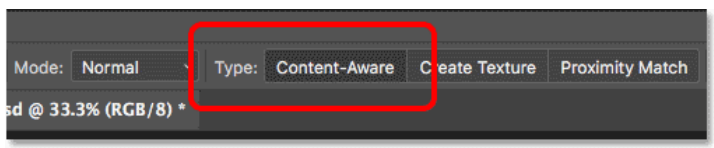

Gambar6.SetelContent-Aware

- Langkah 4: KlikPadaKulit Noda UntukMenghapusnya

Klik pada noda kulit yang tidak diinginkan dengan Spot Healing Brush untuk menghilangkannya. Photoshop akan langsung "menghilangkan" noda dengan mengganti tekstur yang bermasalah dengan tekstur kulit yang bagus dari area sekitarnya. Untuk hasil terbaik, buat kuas sedikit lebih besar dari noda. Untuk mengubah ukuran kuas, tekan tombol braket kanan (]) pada keyboard, untuk memperbesar kuas atau tombol braket kiri (D) untuk membuatnya lebih kecil.

Jika noda belum sepenuhnya hilang pada percobaan pertama, batalkan klik Anda dengan menekan Ctrl + Z (Win) / Command + Z (Mac) pada keyboard, kemudian ubah ukuran kuas jika diperlukan dan klik pada noda yang sama untuk mencoba lagi.

Pada Gambar 2 tampak seperti jerawat tepat di tengah dahi. Petra Sinuraya memposisikan Spot Healing Brush di atasnya, dan membuat sikat sedikit lebih besar dari jerawat itu sendiri.

- Langkah5 :MemposisikanSpot Healing Brush di atasnodakulit.

Untuk menghilangkan noda, dengan Spot Healing Brush. Photoshop menganalisis area yang di edit, menemukan tekstur kulit yang bagus dari area sekitarnya, dan kemudian memadukan tekstur yang bagus dengan tone dan warna asli area masalah.

- Langkah6 :Mengklikuntukmenghilangkannoda.

Petra melakukan hal yang sama dengan noda lain di dahinya, menjaga Spot Healing Brush hanya sedikit lebih besar dari area yang perlu dilembutkan.Selanjutnya dengan Spot Healing Brush untuk membersihkan sisa noda di dahinya.

- Langkah 7 : MenyelesaikanPembersihanKulitAwal

Langkah Terakhir adalah Menyelesaikan pembersihan noda yang ada pada foto. Berikut adalah perbandingan berdampingan kulit setelah perbaikan cepat dengan Spot Healing Brush (kanan) dan sebelum diberi sentuhan Spot Healing Brush (kiri). Bagi Petra, teknik Spot Healing Brush adalah teknik yang cepat dan tidak terlalu rumit untuk proses retouchingfoto.

\section{2) Dodge and Burn - KontrasMencerahkan/Menggelapkan}

Berbeda dengan Burn dan Dodge Tool yang digunakan untuk menyempurnakan mata, kali ini Petra Sinuraya menggunakan Dodge (lighten) dan Burn (darken) untuk foto yang diproses melalui ruang gelap, hal ini dilakukan untuk menciptakan lebih banyak kontras pada gambar akhir. Dengan Dodge dan Burn di Photoshop, Petra Sinuraya selalu berhati-hati dalam menciptakan efek permanen pada lapisan, karena Petra Sinuraya tidak ingin hasil dari karyanya malah merusak warna pada gambar aslinya. Di sini, Petra Sinuraya melihat teknik non-destruktif.

- Langkah 1

Buka gambar di Photoshop. Pada panel Adjustments, klik pada tombol Create New Curves Adjustment Layer. Di panel Layers, ganti nama layer menjadi 'Dodge'

- Langkah 2

Di panel Properties, klik ikon tangan tepat di bawah kata Preset. Temukan tempat paling terang di foto. Lalu klik pada bagian kulit yang paling terang dan seret dengan kursor untuk mencerahkan gambar seperti ini 


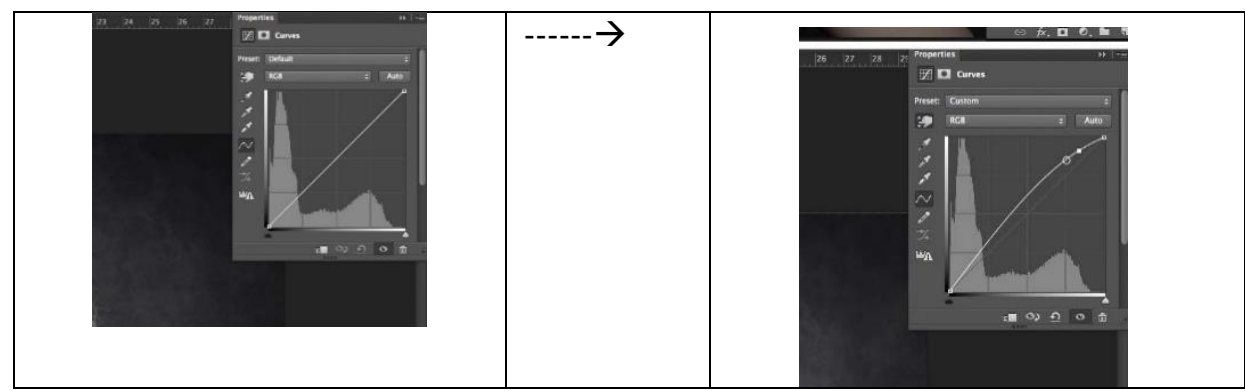

Gambar7. Panel Properties

\section{- Langkah 3}

Petra menggunakan Dodge dan Burn hanya pada area yang dibutuhkan, dari pada menerapkan efek ke seluruh gambar. Untuk melakukan ini, klik pada persegi panjang putih di layer Dodge dan kemudian tekan Cmd / Ctrl + I untuk membalikkannya menjadi hitam.

- Langkah 4

Pada panel Properties, klik ikon tangan tepat di bawah kata Preset lagi. Kali ini, cari area kulit yang paling gelap, dan seret ke bawah dengan kursor Anda untuk menggelapkan gambar.

- Langkah 5

Klik pada persegi panjang putih di layer Burn dan kemudian tekan Cmd / Ctrl + I untuk membalikkannya menjadi hitam.

- Langkah 6

Sekarang setelah Petra menyiapkan layer Dodge dan Burn, Petra mulai memadukan di area Dodge dan Burn yang ingin petra tingkatkan gambar aslinya.

Untuk melakukan ini, pertama-tama pilih kuas besar dengan kekerasan $0 \%$ dan atur warna kuas menjadi putih.

- $\quad$ Langkah 7

Atur brush opacity Anda menjadi 10-20\%. Pilih layer Dodge di panel Layers. Mulailah dengan sapuan besar di sepanjang pipi apel, bagian tengah dahi dan batang hidung.

Bangun efek yang lebih kuat dengan kembali ke area yang sama sebanyak yang diperlukan

- Langkah 8

Untuk Langkah ini fokus pada burning di beberapa bayangan. Beralih kembali ke versi yang lebih besar dari kuas yang sama dan pilih lapisan Bakar di panel Lapisan.

Isi area di bawah tulang pipi - dan di sekitar tepi garis rambut dan rahang - untuk membuat lebih kontras.

- Langkah 9

Sorot kedua layer dan Shift + klik pada ikon AddGroup untuk menambahkannya ke dalam grup. Ubah nama grup menjadi 'Dodge / Burn' dan lanjutkan pengeditan seperti biasa.

Penelitian dilakukan terhadap fotografi Retouching karya Petra Sinuraya. Menurut Petra Sinuraya Pengeditan foto bisa dibilang seperti memasak hidangan. Setiap orang menggunakan pendekatan berbeda dalam membuat hidangan. Beberapa mungkin menambahkan sedikit bumbu dan yang lainnya tanpa melewatkan satu bahan, namun berapun banyaknya bahan yang dimasukan tetap saja hidangan tersebut masih akan disebut dengan nama aslinya. Artinya, dari sebagus apapun dan sebanyak apapun tools yang dituangkan untuk mengedit foto, tatap saja tidak akan merubah nama dari foto tersebut, hanya saja hasil akhir atau kualitas foto lebih menarik.

Retouching gambar atau pengeditan gambar bisa dibilang sangat mirip. Dasarnya mungkin tetap sama tetapi terdapat variasi disetiap gambar yang diedit. Betapapun sempurnanya sebuah gambar menggunakan kamera terbaik, Namun masih ada kekurangan yang perlu dikoreksi terlebih untuk penggunaan komersial.Saat Petra Sinuraya melakukan retouching pada kulit, yang perlu diingat ialah menghilangkan masalah sementara seperti jerawat atau masalah kulit kecil lainnya, bukan untuk menghilangkan fitur permanen seperti tahi lalat atau bahkan bekas luka tertentu. Karena tujuan retouching gambar adalah untuk membantu orang tampil terbaik, bukan

640 http://mahesainstitute.web.id/ojs2/index.php/jehss


membuat mereka terlihat seperti orang lain. Dan lagi, saat melakukan retouching Petra Sinuraya hanya memanfaatkan Tool secukupnya agar hasil lebih terlihat natural.

Setelah proses retouching, klien akan melihat perubahan drastis pada gambar. Cukup dengan koreksi warna, menyesuaikan pencahayaan, gambar terlihat luar biasa. Beberapa teknik retouching Photoshop selalu Petra gunakan agar memberikan gambar yang bagus dan memberikan kepuasan terhadap klien.Setiap Fotografer mempunyai tema Fotografi yang berbeda-beda, Petra Sinuraya dalam menciptakan Retouching foto menggunakan teknik digital meliputi editing dengan bantuan software Photoshop, tentu skill adalah kuncinya. Memiliki pencitraan Retouching memberikan kesan menarik terhadap objek yang Petra Sinuraya Foto. Dengan retouching, gambar yang tidak menarik dengan mudah diubah menjadi gambar yang menarik.

\section{SIMPULAN}

Proses retouching foto close up yang digunakan Petra Sinuraya adalah teknik digital dimana Petra Sinuraya mengasah skill lewat sentuhan Tools yang ada pasa software Photoshop. Peranan komposisi dalam proses retouching sangat penting untuk kebutuhan klien agar foto terlihat lebih menarik di hasil akhir. Adapun hal yang Petra Sinuraya lakukan dalam Retouching foto Close Up ialah dengan berbagai cara seperti Spot Hiling Brush untuk Menghaluskan Kulit, Burn and dodge tool untuk retouching mata, Dodge and Burn untuk Kontras Mencerahkan/Menggelapkan, Filter noise dan Gaussian blur untuk kulit tanpa celah dan Patch tool untuk Menyempurnakan foto.

\section{DAFTAR PUSTAKA}

Agasi, M.R. (2017), Estetika Fotografi Still Life Pada Produk Online Shop Folk Store. Skripsi. Universitas Negeri Yogyakarta.

Agung, M.L. (2011). Element 9 Untuk Pemula. Yogyakarta : Andi Yogyakarta.

Agustin, T., \& Ibrahim, A. (2020). Analisis Kaligrafi Kontemporer Dari Aspek Keterbacaan Huruf Dan Warna. Journal of Education, Humaniora and Social Sciences (JEHSS), 3(1), 187-192. doi:https://doi.org/10.34007/jehss.v3i1.251

Arikunto, S. (2006). Prosedur Penelitian Suatu Pendekatan Praktek. Jakarta: Rineka Cipta.

Dewi, M.S. (2012). Penggunaan Aplikasi Adobe Photoshop dalam Meningkatkan Keterampilan Editing Foto Bagi Anak Tunarungu. E-JUPEKhu. 1(2): 263

Khaeruddin. (2005). Belajar Otodidak Adobe Photoshop CS6. Bandung : CV. Yrama Widya.

Mustika, A., \& Erdansyah, F. (2020). Analisis Ornamen (Gerga) Tradisional Karo pada Bangunan Kantor Bupati Karo Kabupaten Karo. Journal of Education, Humaniora and Social Sciences (JEHSS), 3(1), 161-70. doi:https://doi.org/10.34007/jehss.v3i1.243

Saleh, K. (2014). Fotografi Dasar. Medan: Unimed Press.

Saulaka, O., Mesra, M., \& Daulat, D. (2020). Analisis Kerajinan Boneka Berbahan Koran Bekas Produk Galeri J-ART. Journal of Education, Humaniora and Social Sciences (JEHSS), 3(2), 294-300. doi:https://doi.org/10.34007/jehss.v3i2.205

Setiawan, H. (2015), Analisis Fotografi Digital Imanging Surealistik Karya Kicung Hartono. Skripsi. Universitas Negeri Yogyakarta.

Sinaga, D., \& Triyanto, R. (2020). Tinjauan Ilustrasi Cover Novel Harry Potter Edisi Indonesia Karya Nicolas Fiber Ditinjau Dari Elemen Visual. Journal of Education, Humaniora and Social Sciences (JEHSS), 3(1), 265-272. doi:https://doi.org/10.34007/jehss.v3i1.292

Soelarko, R.M. (1984). Fotografi untuk Pelajar. Yogyakarta: Binacipta.

Sugiyono. (2016). Metode Penelitian Kuantitatif Kualitatif. Dan R\&D. Bandung: Alfabeta.

Yuma, F.M \& Eska, J. (2019). Pelatihan Olah Foto Digital untuk Meningkatkan Kemampuan Peserta Didik dengan Menggunakan Aplikasi Adobe Photoshop CS6 Pada LKP Bintang Mulia Batu Bara. Jurdimas. 2(1): 80

Ziveria, M, Samosir, R.S \& Rusli, M. (2020). Pelatihan Desain Grafis Menggunakan Perangkat Adobe Photoshop untuk Manipulasi Foto Bagi Tim Teknologi Informasi YPU. ABDIMAS. 1(1): 5 